\title{
Study on Lidocaine Inhibiting Proliferation, Migration and Invasion of Breast Cancer Cells by Modulating the MicroRNA-495-3p/Fibroblast Growth Factor 9 Axis
}

\author{
LIZHONG LIN, YIN PAN, MINGMING QUAN AND LINGJUN YANG ${ }^{1 *}$ \\ Department of Oncology, Taizhou Central Hospital (Taizhou University Hospital), ${ }^{1}$ Department of Pain Management, Taizhou \\ Hospital of Zhejiang Province Affiliated to Wenzhou Medical University, Taizhou 317000, China
}

Lin et al.: Study on Lidocaine Inhibiting Proliferation, Migration and Invasion of Breast Cancer Cells

\begin{abstract}
To investigate the mechanism of lidocaine in inhibiting proliferation, migration and invasion of breast cancer cells. Human breast cancer cell line Michigan Cancer Foundation-7 cells were treated with lidocaine. Cell proliferation was detected by 2,5-diphenyl-2H-tetrazolium bromide, cell migration and invasion was detected by Transwell, microRNA-495-3p expression was detected by quantitative reverse transcription polymerase chain reaction and fibroblast growth factor 9, cyclin D1, matrix metalloproteinase 2 and matrix metalloproteinase 9 protein expression were detected by western blot. Human breast cancer cell line Michigan Cancer Foundation-7 cells were transfected with microRNA-495-3p inhibitor or fibroblast growth factor 9 overexpression vector. The effects of silencing microRNA-495-3p or fibroblast growth factor 9 overexpression on proliferation, migration and invasion of human breast cancer cell line Michigan Cancer Foundation-7 cells and the expression of cyclin D1, matrix metalloproteinase 2 and matrix metalloproteinase 9 protein were detected by 2,5-diphenyl-2H-tetrazolium bromide, Transwell and western blot. The dual-luciferase reporter gene experiment confirmed the relationship between microRNA-495-3p and fibroblast growth factor 9 targeting. Lidocaine could inhibit the proliferation, migration and invasion of human breast cancer cell line Michigan Cancer Foundation-7 cells, promote the expression of microRNA495-3p and inhibit the expression of fibroblast growth factor 9 protein in human breast cancer cell line Michigan Cancer Foundation-7 cells. Silencing microRNA-495-3p expression or fibroblast growth factor 9 overexpression decreased the inhibitory effect of lidocaine on proliferation, migration and invasion of human breast cancer cell line Michigan Cancer Foundation-7 cells. MicroRNA-495-3p negatively regulated fibroblast growth factor 9 expression in human breast cancer cell line Michigan Cancer Foundation-7 cells. Silencing fibroblast growth factor 9 expression reversed the effect of microRNA-495-3p silencing on proliferation, migration and invasion of human breast cancer cell line Michigan Cancer Foundation-7 cells treated with lidocaine. Lidocaine inhibits the expression of fibroblast growth factor 9 by up-regulating microRNA-495-3p, thus inhibiting the proliferation, migration and invasion of breast cancer cells.
\end{abstract}

Key words: Lidocaine, breast cancer, microRNA-495-3p, fibroblast growth factor 9, cell proliferation, migration, invasion

Breast cancer is a common life-threatening malignancy in women and the incidence is increasing year by year ${ }^{[1]}$. For the treatment of breast cancer, surgical resection is the main comprehensive treatment. Lidocaine is one of the commonly used local anesthetics, which can inhibit the proliferation, invasion and migration of tumor cells and induce apoptosis in a variety of tumors ${ }^{[2]}$. Low concentrations of lidocaine have been shown to inhibit the migration and invasion of breast cancer cells ${ }^{[3]}$, but the molecular mechanism by which lidocaine

*Address for correspondence

E-mail: yanglj0576@163.com

September-October 2021 exerts its effects is unknown. MicroRNA (miRNA) is a class of small single-stranded non-coding RNA involved in tumorigenesis and tumor development. It has been shown that microRNA-495-3p (miR-495-3p)

This is an open access article distributed under the terms of the Creative Commons Attribution-NonCommercial-ShareAlike 3.0 License, which allows others to remix, tweak, and build upon the work non-commercially, as long as the author is credited and the new creations are licensed under the identical terms

Accepted 15 September 2021

Revised 13 June 2021

Received 01 April 2020

Indian J Pharm Sci 2021;83(5):931-938 
inhibits gastric cancer cell migration by inhibiting the expression of snail and slug, molecules involved in epithelial-to-mesenchymal transition ${ }^{[4]}$. Bioinformatics software showed that Fibroblast Growth Factor 9 (FGF9) was the target gene of miR-495-3p. Currently, there are no reports of the effect of miR-495-3p targeting FGF9 on breast cancer. In this study, lidocaine acts on breast cancer human breast cancer cell line Michigan Cancer Foundation-7 (MCF-7) cells to investigate the molecular mechanism by which lidocaine inhibits proliferation, migration and invasion of breast cancer cells by modulating miR-495-3p/FGF9 expression.

\section{MATERIAL AND METHODS}

\section{Cells and test reagents:}

Breast cancer MCF-7 cells, Shanghai Cell Bank, Chinese Academy of Sciences; fetal bovine serum and Roswell Park Memorial Institute (RPMI) 1640 medium, Gibco USA; Trypsin and 2,5-diphenyl-2HTetrazolium Bromide (MTT), Sigma Company, USA; Lipofectamine $^{\mathrm{TM}} 2000$ kit, Invitrogen, USA; Trizol reagent, reverse transcription kit and Polymerase Chain Reaction (PCR) kit, Shenzhen Jingmei Bioengineering Co., Ltd.; Mouse anti-human Matrix Metalloproteinase-2 (MMP-2) and MMP-9 monoclonal antibodies, Beijing Zhongshan Bioreagent Co., Ltd.; mouse anti-human cyclin D1 monoclonal antibody, Fuzhou Maixin Biotechnology Development Co., Ltd.; rabbit anti-human FGF9 polyclonal antibody, Shanghai Qincheng Biotechnology Co., Ltd.; polyclonal antibody, CST Company, USA; Lipofectamine ${ }^{\mathrm{TM}}$ 2000 kit, Invitrogen, USA; miR-495-3p mimics and negative control, inhibitor and negative control and FGF9 overexpression vector, packaged and synthesized by Shanghai Genechem Co., Ltd.; dual-luciferase activity test kit, Promega company, USA.

\section{Experimental method:}

Cell culture and transfection: MCF-7 cells were recovered, transferred to $25 \mathrm{~cm}^{2}$ flasks and cultured in RPMI 1640 medium with $10 \%$ fetal bovine serum at $37^{\circ}$ in an incubator containing $5 \%$ carbondioxide and $97 \%$ humidity. The medium was changed every 2-3 d. When cells were confluent to $80 \%$, they were subcultured by $0.25 \%$ trypsin digestion. MCF-7 cells in logarithmic growth phase were inoculated in 6 well plates. When the cells fused to $60 \%$, they were transfected with miR-495-3p inhibitor, negative control miR-con, FGF9 overexpression vector (pcDNA-FGF9), empty vector (pcDNA), co-transfected with miR-495-
$3 \mathrm{p}$ inhibitor and si-FGF9, co-transfected with miR495-3p inhibitor and si-con respectively according to the operation instructions of LiPofectamine ${ }^{\mathrm{TM}} 2000$ kit. After $12 \mathrm{~h}$ of transfection, the new culture medium was replaced and cultured for $48 \mathrm{~h}$. miR-495-3p and FGF9 were detected by Quantitative Reverse Transcription Polymerase Chain Reaction (qRT-PCR) and western blot to evaluate the transfection effect. Cells were harvested for subsequent experiments.

Cell grouping: MCF-7 cells were divided into lidocaine group $(0.01,0.05,0.1,0.2 \mathrm{mmol} / 1$ lidocaine treated MCF-7 cells for $24 \mathrm{~h}$ ) and control group (NC group): MCF-7 cells were cultured for $24 \mathrm{~h}$ without any treatment. In addition, $0.1 \mathrm{mmol} / \mathrm{l}$ lidocaine treated MCF-7 cells transfected with miR-495-3p inhibitor, miR-con, pcDNA-FGF9, pcDNA, co-transfected with miR-495-3p inhibitor and si-FGF9, co-transfected with miR-495-3p inhibitor and si-con respectively for $24 \mathrm{~h}$, then lidocaine+anti-miR-495-3p group, lidocaine+antimiR-con group, lidocaine+pcDNA-FGF9 group, lidocaine+pcDNA-con group, lidocaine+anti-miR495-3p+si-FGF9 group and lidocaine+anti-miR-495$3 \mathrm{p}+$ si-con group.

MTT assay for cell proliferation: MCF-7 cells (or transfected MCF-7 cells) were inoculated in 96-well plates at a concentration of $2.5 \times 10^{4}$ cells $/ \mathrm{ml}, 200 \mu \mathrm{l}$ per well. After $12 \mathrm{~h}$ of incubation, it was treated based on grouping as described above in cell grouping. At the end of incubation, $20 \mu \mathrm{l}$ MTT solution with concentration of $5 \mathrm{~g} / \mathrm{l}$ was added to each well and the incubation was continued for $4 \mathrm{~h}$. Suck and discard the culture medium, add $150 \mu$ dimethyl sulfoxide, react for $5 \mathrm{~min}$, mix well and determine the absorbance value (A) at $490 \mathrm{~nm}$ of microplate reader. Cell survival rate $(\%)=\mathrm{A}_{\text {experimental group }}$ $\mathrm{A}_{\text {control group }} \times 100 \%$.

Transwell's ability to detect migration and invasion of cells: Cell migration test-MCF-7 cells (or transfected MCF-7 cells) were inoculated into the upper chamber of Transwell at a concentration of $5 \times 10^{4}$ cells $/ \mathrm{ml}, 100 \mu 1$ per well and $500 \mu \mathrm{l}$ RPMI 1640 medium containing $10 \%$ fetal bovine serum was added to the lower chamber. The upper chamber was grouped according to cell grouping. After $24 \mathrm{~h}$ of incubation, the transwell chamber was removed and the culture fluid was discarded. After fixation with paraformaldehyde and staining with crystal violet, the non-migrating cells were wiped off with a cotton swab and washed with phosphate buffered saline. Make microscopic observation, randomly select 5 fields and make counting. Cell invasion test-Prior to test, dilute Matrigel matrix adhesive and RPMI 1640 
culture medium in the proportion of $1: 8$, place them in the upper chamber of Transwell, dry them naturally, add $100 \mu \mathrm{l}$ cell suspension and then perform the same operation as cell migration test.

Detection of miR-495-3p expression by qRT-PCR: Total RNA was extracted from cells by Trizol reagent and the purity and concentration of RNA were detected by biophotometer. After adjusting the RNA concentration, reversely transcribe the RNA into Complementary DNA (cDNA) according to the reverse transcriptase kit operating instructions. PCR amplification was performed using cDNA as template. PCR amplification procedure: $95^{\circ}$ for $10 \mathrm{~min}, 95^{\circ}$ for $5 \mathrm{~s}, 60^{\circ}$ for $30 \mathrm{~s}$, $72^{\circ}$ for $30 \mathrm{~s}$ and 35 cycles in total. Relative expression levels of miR-495-3p were calculated using the $2^{-\Delta \Delta \mathrm{Ct}}$ method with U6 as an internal reference.

Protein expression by western blot: The total protein in cells was extracted with Radio Immunoprecipitation Assay (RIPA) protein lysing solution and the content of protein was determined by Bicinchoninic Acid (BCA) method. Take proper amount of protein, and boil it at $100^{\circ}$ for $5 \mathrm{~min}$ to denature it. $30 \mu \mathrm{g}$ protein per well was subjected to Sodium Dodecyl SulphatePolyacrylamide Gel Electrophoresis (SDS-PAGE) electrophoresis. After electrophoresis, wet transfer to polyvinylidene difluoride (PVDF) membrane and seal with $5 \%$ skim milk powder for $2 \mathrm{~h}$. FGF9, cyclin D1, MMP-2 and MMP-9 antibodies were added separately and incubated overnight at $4^{\circ}$. The next day, by using Tris-buffered Saline with $0.1 \%$ Tween $^{\circledR} 20$ detergent (TBST) wash the membrane 3 times for 5 min each time. The horseradish peroxidase-labeled secondary antibody was then added and incubated for $1 \mathrm{~h}$ at $37^{\circ}$ in a shaker. After the membrane was washed again with TBST, Enhanced Chemiluminescence (ECL) reagent was added, developed in the dark and photographed with exposure of the gel imaging system.

Dual-luciferase reporter gene experiment validates the relationship between miR-495-3p and FGF9 targeting: TargetScan online software predicts that FGF9's 3'UTR has a nucleotide sequence that binds to miR-495-3p, suggesting that FGF9 is the target gene for miR-495-3p. The 3'UTR sequence of FGF9 containing the miR-495-3p binding site was amplified by PCR to construct the FGF9 wild-type plasmid (FGF9-WT) and the mutant plasmid (FGF9-MUT). FGF9-WT, FGF9MUT, miR-495-3p mimic and negative control were co-transfected into MCF-7 cells, respectively. After $48 \mathrm{~h}$ of transfection, collect cells for lysis and then detect the luciferase activity according to the operation instructions of dual luciferase activity assay kit.

\section{Statistical analysis:}

Statistical Package for the Social Sciences (SPSS) 22.0 software was used to analyze the experimental data. Measurement data were expressed as $(\overline{\mathrm{x}} \pm \mathrm{s})$. Independent sample $t$ test was used for comparison between two groups and one-way analysis of variance was used for comparison among multiple groups. $\mathrm{p}<0.05$ indicated that the difference was statistically significant.

\section{RESULTS AND DISCUSSION}

Compared with NC group, the survival rate of MCF-7 cells in $0.05,0.1$ and $0.2 \mathrm{mmol} / 1$ lidocaine group was significantly decreased $(p<0.05)$. Since the survival rate of MCF-7 cells in the $0.1 \mathrm{mmol} / 1$ lidocaine group was close to $50 \%, 0.1 \mathrm{mmol} / 1$ lidocaine was selected for subsequent experiments. See Table 1.

Compared with $\mathrm{NC}$ group, the migration and invasion of MCF-7 cells in lidocaine group were significantly decreased $(p<0.05)$ and the expression of MMP-2 and MMP-9 protein were significantly decreased $(p<0.05)$. See fig. 1 and Table 2.

The expression of miR-495-3p in MCF-7 cells of lidocaine group was significantly higher than that of $\mathrm{NC}$ group $(\mathrm{p}<0.05)$. miR-495-3p expression was significantly reduced in the lidocaine+anti-miR-495$3 p$ group compared with the lidocaine+anti-miR-con group $(\mathrm{p}<0.05)$, but not in the lidocaine group (with no statistical significance in difference, $p>0.05$ ), indicating successful miR-495-3p transfection and silencing of miR-495-3p expression in MCF-7 cells. Compared with the lidocaine+anti-miR-con group, the survival rate, migration and invasion number, cyclin D1, MMP2 and MMP-9 protein expression of MCF-7 cells in lidocaine+anti-miR-495-3p group were significantly higher $(\mathrm{p}<0.05)$, indicating that silencing miR-495-

\begin{tabular}{|c|c|}
\hline Group & Cell viability (\%) \\
\hline NC group & $100.00 \pm 10.25$ \\
\hline $0.01 \mathrm{mmol} / \mathrm{l}$ & $92.76 \pm 9.38$ \\
\hline $0.05 \mathrm{mmol} / \mathrm{l}$ & $80.28 \pm 8.16^{*}$ \\
\hline $0.1 \mathrm{mmol} / \mathrm{l}$ & $50.05 \pm 5.46^{*}$ \\
\hline $0.2 \mathrm{mmol} / \mathrm{l}$ & $42.53 \pm 4.22^{*}$ \\
\hline
\end{tabular}

Note: Compared with NC group, ${ }^{*} \mathrm{p}<0.05$ 
$3 p$ reduced the inhibitory effect of lidocaine on the protein in lidocaine+pcDNA-FGF9 group was proliferation, migration and invasion of MCF-7 cells.

See fig. 2 and Table 3.

Compared with NC group, the expression of FGF9 protein in MCF-7 cells significantly decreased in lidocaine group $(\mathrm{p}<0.05)$. The expression of FGF9 significantly higher than that in lidocaine+pcDNAcon $(\mathrm{p}<0.05)$, but not in the lidocaine group (with no statistical significance in difference, $\mathrm{p}>0.05)$, indicating that FGF9 overexpression vector was successfully transfected and the expression of miR495-3p in MCF-7 cells was silenced. Compared with
A

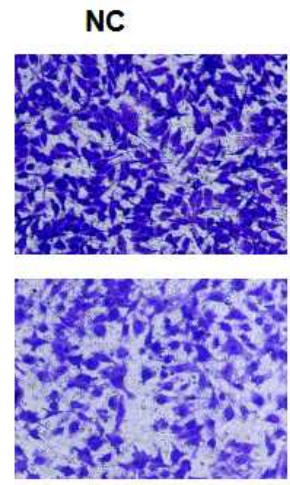

B

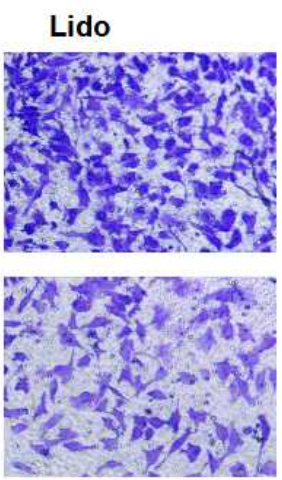

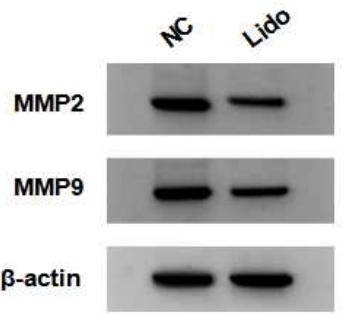

Fig. 1: Effect of lidocaine on migration and invasion of breast cancer cell line MCF-7

Note: (A) Transwell detection of migration and invasion of MCF-7 cells; (B) Western blot detection of MMP2 and MMP9 protein expression in MCF-7 cells

TABLE 2: EFFECT OF LIDOCAINE ON MIGRATION AND INVASION OF BREAST CANCER CELL LINE MCF-7 $(x \pm s, n=9)$

\begin{tabular}{lcccc}
\hline Group & MMP-2 & MMP-9 & Number of cells migrating & Number of invasive cells \\
\hline NC & $1.05 \pm 0.11$ & $0.86 \pm 0.08$ & $330.48 \pm 33.05$ & $150.33 \pm 15.04$ \\
Lidocaine & $0.40 \pm 0.04^{*}$ & $0.35 \pm 0.05^{*}$ & $162.46 \pm 16.25^{*}$ & $81.76 \pm 8.18^{*}$
\end{tabular}

Note: Compared with NC, ${ }^{*} \mathrm{p}<0.05$

A
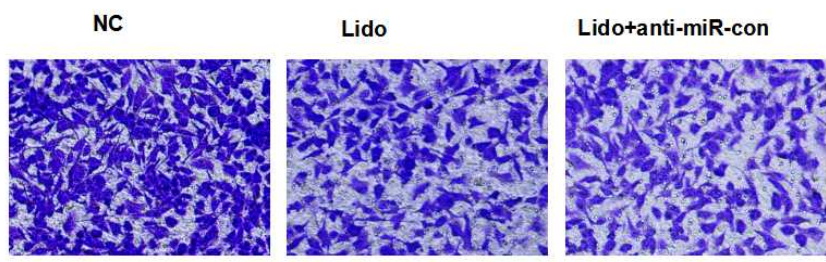

Lido+anti-miR-495-3p
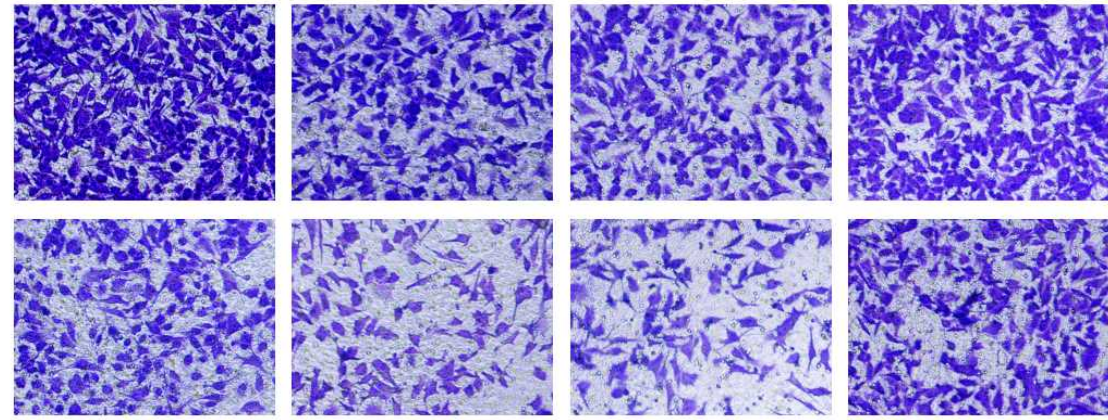

B

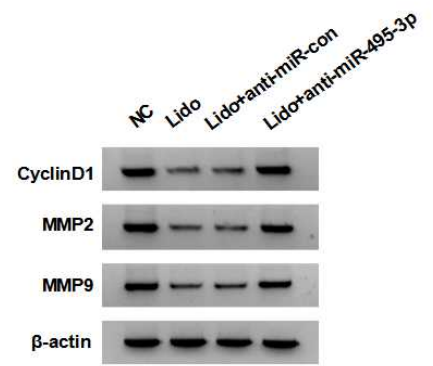

Fig. 2: Expression of CyclinD D1, MMP2, MMP9 proteins in silencing miR-495-3p by western blot 
the lidocaine+pcDNA-con group, the survival rate, migration and invasion number, protein expression of cyclin D1, MMP-2 and MMP-9 of MCF-7 cells in the lidocaine+pcDNA-FGF9 group were significantly increased $(p<0.05)$, indicating that overexpression of FGF9 decreased the inhibitory effect of lidocaine on the proliferation, migration and invasion of MCF-7 cells. See fig. 3 and Table 4.
TargetScan online software predicts that FGF9's 3'UTR has a nucleotide sequence that binds to miR-495-3p, suggesting that FGF9 is the target gene for miR-495-3p (fig. 4A). The dual-luciferase activity assay showed that the luciferase activity of the FGF9 wild-type plasmid was significantly reduced in the miR-495-3p group compared to the miR-con group $(\mathrm{p}<0.05)$, whereas

TABLE 3: EFFECT OF SILENCING miR-495-3P ON PROLIFERATION, MIGRATION AND INVASION OF LIDOCAINE TREATED BREAST CANCER CELL LINE MCF-7 $(x \pm s, n=9)$

\begin{tabular}{|c|c|c|c|c|c|c|c|}
\hline Group & $\operatorname{miR}-495-3 p$ & Cyclin D1 & MMP-2 & MMP-9 & Cell viability (\%) & $\begin{array}{c}\text { Number of cells } \\
\text { migrating }\end{array}$ & $\begin{array}{c}\text { Number of } \\
\text { invasive cells }\end{array}$ \\
\hline Nc & $1.00 \pm 0.12$ & $1.20 \pm 0.15$ & $1.02 \pm 0.11$ & $0.88 \pm 0.08$ & $100.12 \pm 10.04$ & $326.15 \pm 30.93$ & $153.84 \pm 10.95$ \\
\hline $\begin{array}{l}\text { Lidocaine } \\
\text { lidocaine }\end{array}$ & $1.96 \pm 0.20^{*}$ & $0.45 \pm 0.05^{*}$ & $0.42 \pm 0.04^{*}$ & $0.32 \pm 0.03^{*}$ & $51.33 \pm 5.14^{*}$ & $159.59 \pm 10^{*}$ & $81.48 \pm 9.81^{*}$ \\
\hline $\begin{array}{l}\text { Lidocaine+anti- } \\
\text { miR-con }\end{array}$ & $2.05 \pm 0.21$ & $0.43 \pm 0.04$ & $0.38 \pm 0.03$ & $0.35 \pm 0.06$ & $50.46 \pm 5.05$ & $160.18 \pm 15.97$ & $81.10 \pm 7.08$ \\
\hline $\begin{array}{l}\text { Lidocaine+anti- } \\
\text { miR-495-3p }\end{array}$ & $1.24 \pm 0.13^{\#}$ & $1.02 \pm 0.10^{\#}$ & $0.88 \pm 0.08^{\#}$ & $0.72 \pm 0.07^{\#}$ & $89.04 \pm 9.02^{\#}$ & $290.84 \pm 44.90^{\#}$ & $134.85 \pm 15.57^{\#}$ \\
\hline
\end{tabular}

Note: Compared with NC group, * $\mathrm{p}<0.05$; compared with lidocaine+anti-miR-con group, ${ }^{*} \mathrm{p}<0.05$

A

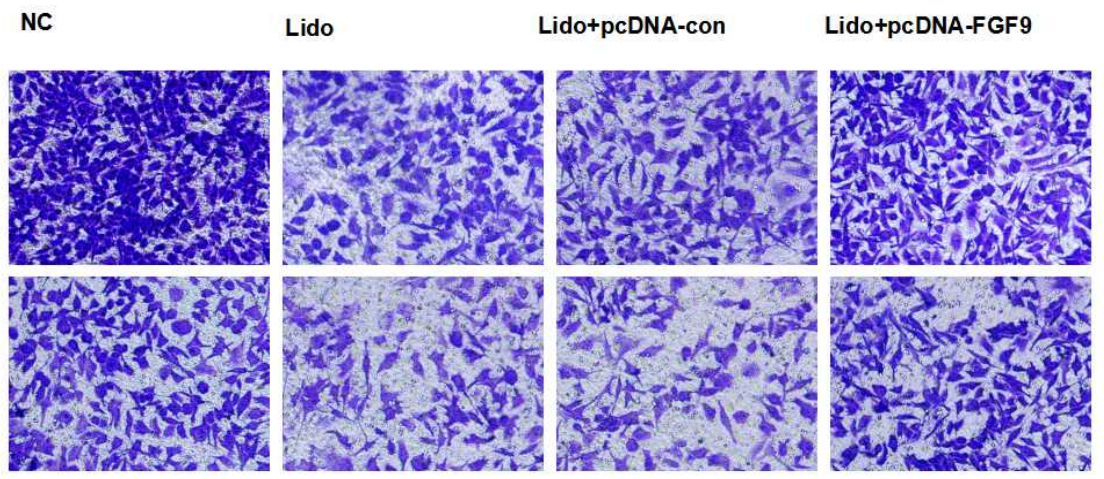

$\mathbf{B}$

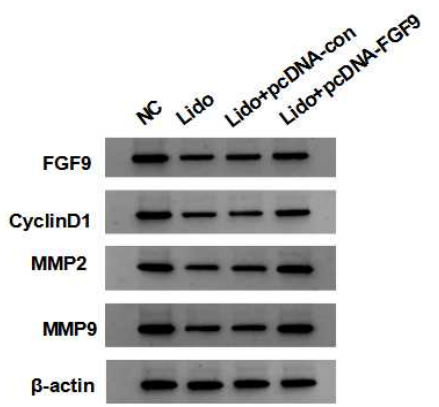

Fig. 3: Expression of FGF9, CyclinD1, MMP2 and MMP9 proteins in overexpression FGF9 by western blot

TABLE 4: EFFECT OF OVEREXPRESSION FGF9 ON PROLIFERATION, MIGRATION AND INVASION OF LIDOCAINE TREATED BREAST CANCER CELL LINE MCF-7 $(x \pm s, n=9)$

\begin{tabular}{lccccccc}
\hline Group & FGF9 & Cyclin D1 & MMP-2 & MMP-9 & $\begin{array}{c}\text { Cell viability } \\
(\%)\end{array}$ & $\begin{array}{c}\text { Number of } \\
\text { cells migrating }\end{array}$ & $\begin{array}{c}\text { Number of } \\
\text { invasive cells }\end{array}$ \\
\hline NC & $0.99 \pm 0.10$ & $1.22 \pm 0.12$ & $1.00 \pm 0.10$ & $0.90 \pm 0.09$ & $101.63 \pm 9.57$ & $329.88 \pm 21.79$ & $150.44 \pm 15.26$ \\
Lidocaine & $0.36 \pm 0.04^{*}$ & $0.43 \pm 0.05^{*}$ & $0.38 \pm 0.04^{*}$ & $0.34 \pm 0.03^{*}$ & $51.56 \pm 5.76^{*}$ & $166.23 \pm 15.40^{*}$ & $80.57 \pm 7.24^{*}$ \\
Lidocaine+pcDNA-con & $0.38 \pm 0.05$ & $0.42 \pm 0.06$ & $0.40 \pm 0.05$ & $0.36 \pm 0.04$ & $50.44 \pm 4.95$ & $166.99 \pm 12.41$ & $79.48 \pm 9.09$ \\
Lidocaine+pcDNA-FGF9 & $0.86 \pm 0.08^{\#}$ & $0.96 \pm 0.10^{\#}$ & $0.82 \pm 0.08^{\#}$ & $0.78 \pm 0.07^{\#}$ & $80.47 \pm 7.39^{\#}$ & $280.10 \pm 12.38^{\#}$ & $114.31 \pm 13.32^{\#}$
\end{tabular}

Note: Compared with NC group, ${ }^{*} \mathrm{p}<0.05$; compared with lidocaine+pcDNA-con group, ${ }^{\#} \mathrm{p}<0.05$ 
the luciferase activity of the FGF9 wild type plasmid was not significantly altered $(p>0.05)$, indicating that miR-495-3p binds to the 3'UTR target of FGF9 (Table 5). FGF9 protein levels were significantly lower in the miR-495-3p group than in the miR-con group $(p<0.05)$ and FGF9 protein levels were significantly higher in the anti-miR-495-3p group than in the antimiR-con group $(\mathrm{p}<0.05)$, further indicating that miR495-3p targets down-regulated FGF9 expression (fig. 4B and Table 6).

Compared with the lidocaine+anti-miR-495-3p+si-con group, the survival, migration and invasion, cyclin D1, MMP-2 and MMP-9 protein expression of MCF-7 cells in the lidocaine+anti-miR-495-3p+si-FGF9 group were significantly reduced $(\mathrm{p}<0.05)$, indicating that silencing FGF9 partially reversed the effects of silencing miR495-3p on proliferation, migration and invasion of MCF-7 cells treated with lidocaine (fig. 5 and Table 7).

The use of narcotic drugs may affect the postoperative outcome and prognosis of tumor patients. The selection of narcotic drugs which can inhibit the growth and

TABLE 5: DETECTION RESULTS OF DUALLUCIFERASE ACTIVITY ( $x \pm s, n=9)$

\begin{tabular}{lcc}
\hline \multirow{2}{*}{ Group } & \multicolumn{2}{c}{ Luciferase activity } \\
\cline { 2 - 3 } & WT & MUT \\
\hline miR-con & $1.00 \pm 0.10$ & $1.00 \pm 0.10$ \\
miR-495-3p & $0.18 \pm 0.02^{*}$ & $1.03 \pm 0.10$ \\
\hline
\end{tabular}

Note: Compared with miR-con group, ${ }^{*} p<0.05$ metastasis of tumor cells at the time of surgery may reduce the incidence of postoperative recurrence and metastasis ${ }^{[5]}$. The cell cycle is the basic process of cell life activity and the process accelerates cell proliferation. Cyclin D1 is a key regulator of the cell cycle and is involved in cell proliferation ${ }^{[6]}$. The migration and invasion of tumor cells are closely related to the degradation of extracellular matrix. Matrix metalloproteinases are enzymes that degrade extracellular matrix and promote migration and invasion of tumor cells ${ }^{[7]}$. Zhang et al. ${ }^{[8]}$ showed that lidocaine inhibited the proliferation of lung cancer cells by down-regulating the expression of Golgi Transport 1A (GOLT1A). This study showed that the expression of cyclin D1, MMP-2 and MMP-9 in MCF-9 cells treated with lidocaine decreased and the survival rate, migration and invasion number of MCF-9 cells decreased, indicating that lidocaine inhibited the proliferation, migration and invasion of MCF-7 cells, which was consistent with the reported results ${ }^{[9]}$. This study also showed that lidocaine promoted miR-495$3 p$ expression and inhibited FGF9 protein expression in breast cancer cells, suggesting that lidocaine may act by modulating miR-495-3p and FGF9 expression.

miRNA is ubiquitous in eukaryotes and is involved in regulating malignant biological behaviors such as proliferation, apoptosis, migration and invasion of tumor cells. MiR-495-3p, a member of miRNA, has been shown to decrease expression of miR-495-3p in

A

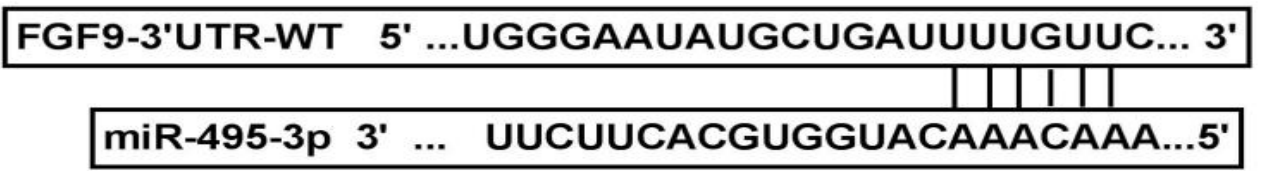

FGF9-3'UTR-MUT 5'... UGGGAAUAUGCUGAUGCGUCGC... 3'

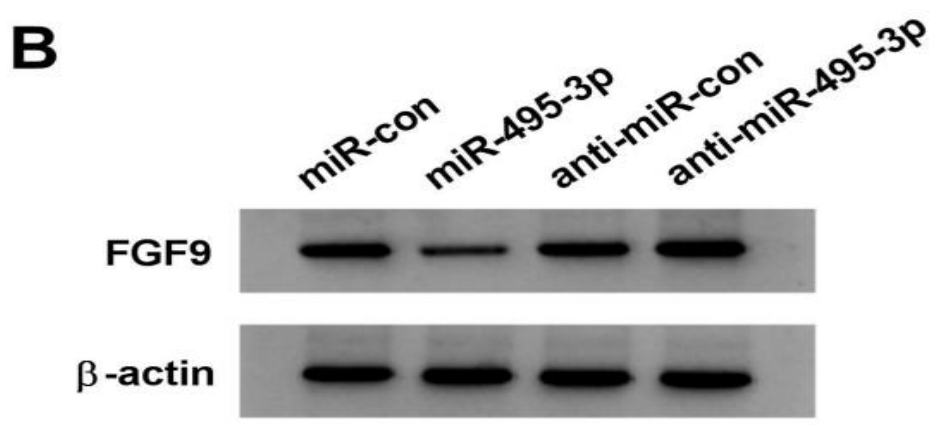

Fig. 4: miR-495-3p targeted regulation of FGF9 expression

Note: (A) TargetScan software predicts that 3'UTR of FGF9 has a nucleotide sequence that binds to miR-495-3p; (B) FGF9 protein expression is detected by western blot 
TABLE 6: EFFECT OF miR-495-3P ON FGF9 PROTEIN EXPRESSION IN MCF-7 CELLS ( $x \pm s, n=9$ )

\begin{tabular}{lc}
\hline Group & FGF9 \\
\hline miR-con & $1.00 \pm 0.10$ \\
miR-495-3p & $0.38 \pm 0.04^{*}$ \\
Anti-miR-con & $1.03 \pm 0.15$ \\
Anti-miR-495-3p & $1.32 \pm 0.13^{\#}$ \\
\hline
\end{tabular}

Note: Compared with miR-con group, ${ }^{*} p<0.05$; compared with the anti-miR-con group, ${ }^{\#} \mathrm{p}<0.05$ colon cancer cells and inhibit cell cycle progression and induce apoptosis by up-regulating expression of miR$495-3 p$ in colon cancer cells ${ }^{[10]}$. Up-regulation of miR495-3p expression inhibits proliferation and invasion of renal cell carcinoma cells and is a potential therapeutic target in renal cell carcinoma ${ }^{[11]}$. Currently, the impact of miR-495-3p on breast cancer is unknown. Here, we show that silencing miR-495-3p expression inhibits

A
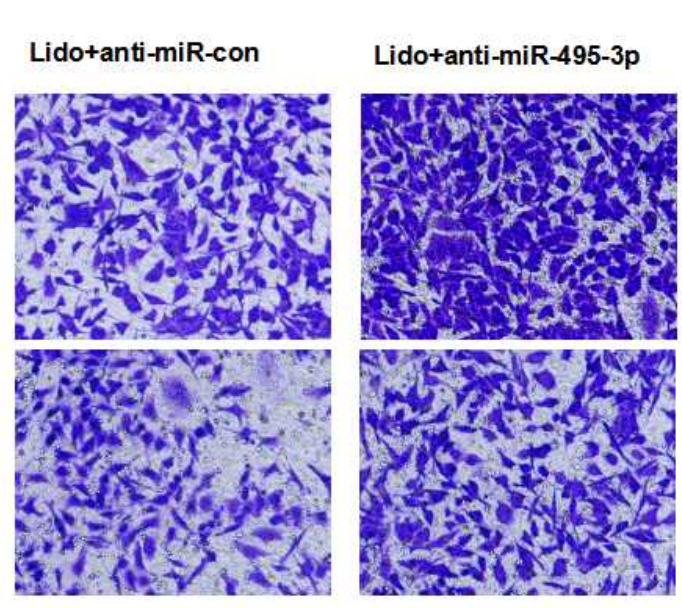

Lido+anti-miR-495-3p+ si-con
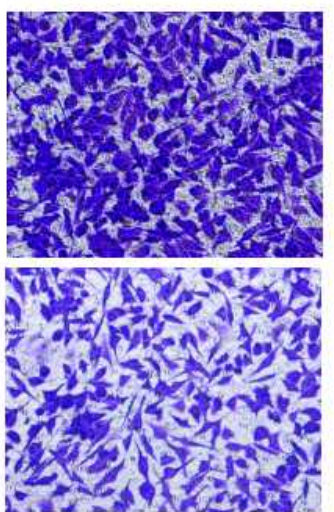
+si-FGF9

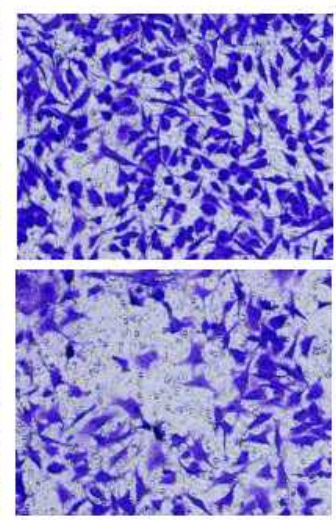

B

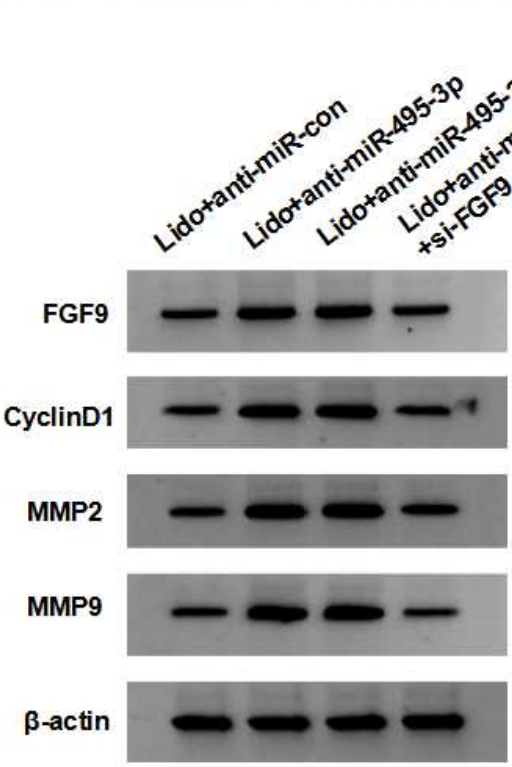

Fig. 5: Western blot assay for FGF9, Cyclin D1, MMP2, MMP9 protein expression

TABLE 7: SILENCING FGF9 PARTIALLY REVERSES THE EFFECT OF SILENCING miR-495-3P ON PROLIFERATION, MIGRATION AND INVASION OF LIDOCAINE-TREATED BREAST CANCER CELL LINE MCF-7 (x $\pm s, n=9)$

\begin{tabular}{lccccccc}
\hline Group & FGF9 & Cyclin D1 & MMP-2 & MMP-9 & $\begin{array}{c}\text { Cell viability } \\
(\%)\end{array}$ & $\begin{array}{c}\text { Number of cells } \\
\text { migrating }\end{array}$ & $\begin{array}{c}\text { Number of } \\
\text { invasive cells }\end{array}$ \\
\hline Lidocaine+anti-miR-con & $0.38 \pm 0.04$ & $0.43 \pm 0.04$ & $0.36 \pm 0.05$ & $0.33 \pm 0.03$ & $100.66 \pm 9.51$ & $164.03 \pm 13.96$ & $80.94 \pm 6.26$ \\
Lidocaine+anti-miR-495-3p & $0.88 \pm 0.09^{*}$ & $1.02 \pm 0.10^{*}$ & $0.86 \pm 0.08^{*}$ & $0.70 \pm 0.07^{*}$ & $148.79 \pm 13.49^{*}$ & $302.93 \pm 28.78^{*}$ & $145.08 \pm 19.56^{*}$ \\
$\begin{array}{l}\text { Lidocaine+anti-miR-495- } \\
\text { 3p+si-con }\end{array}$ & $0.92 \pm 0.10$ & $1.00 \pm 0.12$ & $0.85 \pm 0.09$ & $0.75 \pm 0.08$ & $148.55 \pm 16.26$ & $301.04 \pm 29.09$ & $145.19 \pm 7.99$ \\
$\begin{array}{l}\text { Lidocaine+anti-miR-495- } \\
\text { 3p+si-FGF9 }\end{array}$ & $0.48 \pm 0.0^{\#}$ & $0.60 \pm 0.0^{\#}$ & $0.45 \pm 0.05^{\#}$ & $0.42 \pm 0.0^{\#}$ & $108.99 \pm 9.88^{\#}$ & $198.39 \pm 12.29^{\#}$ & $94.32 \pm 8.74^{\#}$ \\
\hline
\end{tabular}

Note: Compared with lidocaine+anti-miR-con group, ${ }^{*} \mathrm{p}<0.05$; compared with lidocaine+anti-miR-495-3p+si-con group, ${ }^{\#} \mathrm{p}<0.05$ 
lidocaine inhibition of proliferation, migration and invasion in breast cancer MCF-7 cells, suggesting that lidocaine inhibits proliferation, migration and invasion by up-regulating miR-495-3p expression in breast cancer MCF-7.

miRNA typically binds to 3'UTR of target mRNA to inhibit target mRNA translation or degradation of target mRNA, thereby modulating gene expression and affecting vital activity ${ }^{[12]}$. TargetScan online software predicts that FGF9's 3'UTR has a nucleotide sequence that binds to miR-495-3p, suggesting that FGF9 is the target gene for miR-495-3p. This study demonstrates that miR-495-3p binds to the 3'UTR target of FGF9 by dual-luciferase reporter gene experiment and upregulates miR-495-3p expression in breast cancer cells with reduced FGF9 expression, down-regulated miR495-3p expression and increased FGF9 expression, indicating that miR-495-3p targets down-regulated FGF9 expression in breast cancer cells. Activation of the FGF-beta signal pathway has been shown to promote tumorigenesis and tumor development ${ }^{[13]}$. FGF9 is one of the related factors of FGF- $\beta$ signal pathway and plays an important role in tumorigenesis and tumor development. Studies have shown that miR187 inhibits growth of cervical cancer cells by targeting down-regulation of FGF9 expression ${ }^{[14]}$; miR-4317 inhibits growth and metastasis of non-small cell lung cancer cells by targeting FGF9 and cyclin D2 ${ }^{[15]}$. Our results suggest that overexpression of FGF9 inhibits the inhibitory effect of lidocaine on the proliferation, migration and invasion of breast cancer MCF-7 cells. Silencing FGF9 partially reverses the effects of silencing miR-495-3p on the proliferation, migration and invasion of lidocaine-treated MCF-7 breast cancer cells, further indicating that lidocaine inhibits the expression of FGF9 by up-regulating the expression of miR-495-3p, thereby inhibiting the proliferation, migration and invasion of breast cancer cells.

In conclusion, lidocaine inhibits proliferation, migration and invasion of breast cancer cells, which may play a role by up-regulating miR-495-3p expression in cells and thereby inhibiting FGF9 expression.

\section{Conflict of interests:}

The authors declared no conflicts of interest.

\section{REFERENCES}

1. Wen D, Wen X, Yang Y, Chen Y, Wei L, He Y, et al. Urban rural disparity in female breast cancer incidence rate in China and the increasing trend in parallel with socioeconomic development and urbanization in a rural setting. Thorac Cancer 2018;9(2):262-72.

2. Chang YC, Hsu YC, Liu CL, Huang SY, Hu MC, Cheng SP. Local anesthetics induce apoptosis in human thyroid cancer cells through the mitogen-activated protein kinase pathway. PloS one 2014;9(2):e89563.

3. Qin Z, Jianxin H, Min X. Study on the effect and mechanism of lidocaine on inhibiting the invasion of breast and prostate cancer cells. Mod Prev Med 2019;46 (1):138-44.

4. Kim MG, Kim SJ, Bae HJ, Noh JH, Kim JK, Eun JW, et al. MicroRNA-495-3p functions as tumor suppressor by targeting multiple oncogenic epigenetic effector molecules in gastric cancer. Cancer Res 2013;73(8):5290.

5. Zhang N, Liu Y, Yang C. Research progress on the effect of propofol on_tumor. Chin J Clin Pract Med 2016;7(3):102-4.

6. Zhong L, Li N, Liu H. LncRNA RP1 promotes the proliferation of colon cancer cells by regulating cell cycle proteins. Chin J Biochem Mol Biol 2018;34(10):111-8.

7. Piromkraipak P, Sangpairoj K, Tirakotai W, Chaithirayanon K, Unchern S, Supavilai P, et al. Cysteinyl leukotriene receptor antagonists inhibit migration, invasion and expression of MMP-2/9 in human glioblastoma. Cell Mol Neurobiol 2018;38(2):559-73.

8. Zhang L, Hu R, Cheng Y, Wu X, Xi S, Sun Y, et al. Lidocaine inhibits the proliferation of lung cancer by regulating the expression of GOLT 1A. Cell Prolif 2017;50(5):e12364.

9. Ye L, Zhang Y, Chen YJ, Liu Q. Anti-tumor effects of lidocaine on human gastric cancer cells in vitro. Bratisl Lek Listy 2019;120(3):212-7.

10. He Z, Dang J, Song A, Cui X, Ma Z, Zhang Z. NEAT1 promotes colon cancer progression through sponging miR-495-3p and activating CDK6 in vitro and in vivo. J Cell Physiol 2019;234(11):19582-91.

11. Wang LN, Zhu XQ, Song XS, Xu Y. Long noncoding RNA lung cancer associated transcript 1 promotes proliferation and invasion of clear cell renal cell carcinoma cells by negatively regulating miR-495-3p. J Cell Biochem 2018;119(9):7599609.

12. Sun M, Ding J, Li D, Yang G, Cheng Z, Zhu Q. NUDT21 regulates 3 -UTR length and microRNA-mediated gene silencing in hepatocellular carcinoma. Cancer Lett 2017;410:158-68.

13. Ji W, Zhao Y, Zhang F. Progression of TGF- $\beta$ interaction with intracellular signaling pathway in tumor research. Chin $\mathrm{J}$ Oncol Clin 2018;45(15):44-7.

14. Liang H, Luo R, Chen X, Zhao Y, Tan A. miR-187 inhibits the growth of cervical cancer cells by targeting FGF9. Oncol Rep 2017;38(4):1977-84.

15. He X, Chen SY, Yang Z, Zhang J, Wang W, Liu MY, et al. miR-4317 suppresses non-small cell lung cancer (NSCLC) by targeting fibroblast growth factor 9 (FGF9) and cyclin D2 (CCND2). J Exp Clin Cancer Res 2018;37(1):1-6. 